\title{
Repensar el "Proceso". Debates en torno a la dictadura y sus vínculos con el presente
}

Reseña de: The Argentinian Dictatorship and its Legacy. Rethinking the Proceso de Juan Grigera y Luciana Zorzoli (editores), Palgrave Macmillan, 2019, 213 págs.

\author{
Victoria Estermann \\ victoria.estermann@gmail.com \\ Instituto de Investigaciones en Humanidades y \\ Ciencias Sociales - Universidad Nacional de La \\ Plata, Argentina \\ Universidad de Rostock, Alemania
}

Cita sugerida: Estermann, V. (2021). Repensar el "Proceso". Debates en torno a la dictadura y sus vínculos con el presente [Revisión del libro The Argentinian Dictatorship and its Legacy. Rethinking the Proceso por Juan Grigera y Luciana Zorzoli (Eds.)]. Sociohistórica, 47, e138. https://doi.org/10.24215/18521606e138

El libro de Juan Grigera y Luciana Zorzoli reúne una colección de trabajos presentados en la conferencia "Rethinkingthe 'proceso'. The argentinian dictatorship in perspective (1976-1983)" realizada en el Instituto de las Américas del University College London, el 24 de marzo de 2016, cuando se cumplían 40 años del comienzo del último golpe militar. Asimismo, se inscribe en una colección más amplia, "Studies of the Americas", editada por Maxine Molyneux (socióloga feminista especializada en sociología política, género y desarrollo), donde se reúnen investigaciones transdisciplinarias, estudios comparativos y de casos sobre América Latina, el Caribe y Estados Unidos, en las áreas de ciencia política, economía, historia, sociología, antropología, desarrollo, género, políticas sociales y recursos naturales.

El resultado es una pequeña muestra de las discusiones que han surgido en los últimos decenios donde se repiensa la experiencia de la dictadura en Argentina así como sus vínculos con la actualidad. Para los editores, el estallido social del 2001 y elcambio en las políticas de derechos humanos a partir de 2003, así como el aumento del financiamiento para los proyectos relacionados con dichas temáticas junto con la 
desclasificación y apertura de varios archivos se combinaron con el desarrollo de una nueva forma de pensar el estudio de la Historia Reciente (el abordaje de un pasado traumático que interpela al presente y la revisión de la caja de herramientas que usaba tradicionalmente la disciplina histórica) para dar lugar a un campo prolífico de investigaciones acerca de ese tan mencionado "pasado que no pasa" donde se encuadra el texto presentado.

Para encarar la reseña de este libro, agruparemos los capítulos según ejes temáticos que reconocemos como transversales a los mismos. En primer lugar, los capítulos dos, tres y cuatro pueden pensarse desde la discusión de la elección de la escala en cuanto al objeto de estudio, y cómoavanzar en investigaciones que rompan con la imagen centrada en Buenos Aires, para incorporar complejidad y nuevos análisis a objetos de estudio ya abordados.

Para comenzar, el capítulo dos, “A Foundation of Terror: Tucumán and the Proceso, 1975-1983”, escrito por James H. Schrader,es uno de los más novedosos e interesantes del libro. Realiza un aporte original al período que abre el "Operativo Independencia". El autor no sitúa a este acontecimiento como un mero antecedente o un ensayo, sino que piensa el rol de los discursos modernizadores y desarrollistas, señalándolo como una "práctica de construcción de la Nación a través del asesinato en masa y la modernización, único a Tucumán" (p.24). Así es como también menciona al terror desplegado como "castigos colectivos" que se aplican a través de los familiares, entendidos como responsables por las acciones y comportamientos de sus miembros. A través del estudio del caso tucumano, el autor desarrolla por un lado una crítica al "Whitewash" del siglo XX, revalidando al racismo como un concepto para operar y entender el entramado de la Argentina en ese período. Por otro lado, permite inscribir al "Operativo Independencia" como un "laboratorio de la guerra fría”, situándolo en consonancia con las disputas políticas que se daban a nivel internacional y vinculando su historia con el rol específico que tuvo la provincia en la construcción de proyectos nacionales, tanto dentro del peronismo como de los proyectos de "desperonización".

El tercer capítulo, "Anti-subversive Repression and Dictatorship in Argentina: An Approach from Northern Patagonia” de Pablo Scatizza, nos adentra explícitamente en la discusión sobre la importancia de modificar la escala para complejizar la teorización acerca de los circuitos represivos durante la dictadura. Para esto el autor analiza cómo se operó en el norte de la Patagonia, discutiendo con el sentido común sobre la baja o nula actividad represiva de la zona. Además, se permite describir y señalar un patrón específico de detención clandestina, cuando indaga sobre las diferencias entre los Centros Clandestinos de Detención y los Centros de Detención Clandestina. Situando a estos últimos como un elemento clave a la hora de comprender el dispositivo represivo en su totalidad. Por último, y también a través del estudio del mismo caso, se plantea la discusión acerca de los diferentes grados de autonomía relativa en las fuerzas policiales y de seguridad que no obstante no fueron en desmedro de la sistematicidad del plan.

Al cuarto capítulo, llamado "Economic Policy and Global Change: The Puzzle of Industrial Policy Under the Proceso" y escrito por Juan Grigera, también lo englobamos en este eje para repensar la escala, debido al planteo de la importancia de analizar el contexto supranacional para poder abarcar la complejidad de la política industrial llevada adelante por la dictadura y sus resultados. El capítulo se divide en tres partes. Primero, hace una revisión de las principales interpretaciones de la dirección, intenciones y consecuencias de la política económica del 'Proceso'. El autor plantea a la represión como una condición necesaria para la implementación del plan económico y la importancia de la crisis internacional de 1973 y los cambios en los patrones de acumulación global para el análisis de la política económica, destacando, a modo de crítica, la ausencia de estas temáticas en los estudios revisados.

En la segunda parte, el autor compara los programas de política industrial previos y durante la dictadura, señalando la importancia quetomaron en el así llamado Proceso de Reorganización Nacional. Recuperar el caso de Tierra del Fuego en la última parte del artículo le permite ejemplificar esta oleada de políticas ubicándola dentro de la reestructuración de algunos sectores como requisito del capitalismo mundial en la etapa posterior a1970, para integrarla a las cadenas de valor global y para localizar al capital donde la tradición 
sindical era baja o inexistente. Esto permitiría explicar la continuidad del plan económico de la dictadura más allá del buen o mal funcionamiento de las políticas aplicadas por el régimen.

A los capítulos cinco y seis los englobamos dentro del estudio de temáticas y fuentes innovadoras. Ambos artículos iluminan sobre aspectos poco investigados de la dictadura, como son el federalismo y la conformación de leyes, por un lado, y el control y la censura del cine en la dictadura en relación con el género, por el otro.

En el capítulo cinco ("Law-Making and Federalism in Argentina's Last Dictatorship") Alejandro Bonvecchi y Emilia Simison mencionan la poca atención que se le ha dado al funcionamiento de las instituciones políticas bajo períodos autoritarios y su efecto en la realización de las leyes. Para demostrar cómo estas instituciones dan forma al proceso legislativo y sus resultados los autores estudian el caso argentino, donde el régimen tendió a la distribución del poder para institucionalizar el balance del mismo en la elite gobernante, con el objetivo de evitar la experiencia de la dictadura anterior y el faccionalismo.

A través del análisis cuantitativo e incluyendo el estudio de casos acerca del proceso de creación de leyes entre 1976-1983 (posibilitado por la desclasificación de los documentos de la Comisión de Asesoramiento Legislativo, CAL) los autores demuestran que, mientras más colectiva es la estructura ejecutiva y mientras más tendiente a compartir el poder sea el régimen, más probable es que los cuerpos legislativos enmienden o rechacen iniciativas ejecutivas. Esto agrega una cuota de complejidad a los estudios en ciencia política sobre autoritarismo, ya que tradicionalmente se piensa a las dictaduras como la concentración del poder en una sola persona con capacidad absoluta para determinar las leyes del país.

El capítulo seis se llama "State, Filmmaking and Sexuality during the Military Dictatorship in Argentina (1976-1983)”. Escrito por Debora D’Antonio, hace un recorrido por la política cinematográfica desde 1933 mencionando las distintas formas de control y fomento de la industria nacional. Luego se enfoca en las herramientas que tuvo la dictadura militar de 1976 para promocionar e incentivar la producción de películas nacionales.

La autora menciona una paradoja entre la función que la dictadura le asignaba (ser un soporte moral que permitiera a la audiencia distanciarse de la realidad política y social del país) y el análisis que ella hace de dos comedias eróticas producidas en ese período, donde señala la incompatibilidad de las mismas con los objetivos culturales del régimen, ya que se exhortaba al adulterio y se devaluaban las figuras parentales.

En ese sentido, D’Antonio concluye, por un lado, que esta contradicción no se concebía como una amenaza al orden social, ya que el corolarioera siempre la vuelta al status quo y la reivindicación de la familia y de los roles de género en el matrimonio. Por el otro, y centrándose en la gran cantidad de comedias eróticas en manos de muy pocas productoras que se estrenaron en ese período, menciona la ambigüedad de la censura oficial, donde la aprobación o node las mismas pasaba más por el nepotismo y la corrupción de los oficiales del régimen antes que porsu contenido.

Los últimos capítulos se engloban dentro del eje "tensiones y contradicciones" porque son una serie de trabajos que abordan, desde una nueva perspectiva, temáticas con un interesante recorrido académico, permitiendo destacar las tensiones al interior de los mismos.

El capítulo siete, llamado "Rethinking Trade Unions" y escrito por Luciana Zorzoli, puede dividirse en tres partes. En la primera se recorren los estudios clásicos sobre sindicatos en la dictadura planteando la discusión entre 'quietismo' y 'oposición' a la hora de comprender el accionar de los mismos, señalando que no se tuvieronen cuenta las diferencias regionales ni sectoriales. Por ello la autora menciona que ninguna de las dos posturas captura la imagen global de los eventos ocurridos en el movimiento sindical.

En la segunda parte plantea la postura de que la pérdida de poder por parte de los liderazgos del sindicalismo ortodoxo no fue similar a la experimentada por el conjunto de la clase trabajadora,ya que los objetivos de las intervenciones sindicaleseran, por un lado, desmantelar específicamente a los sindicatos del sindicalismo opositor (combativo, clasista, revolucionario),así como disciplinar al movimiento sindical peronista ortodoxo para forzarlos a adaptar sus prácticas a una nueva distribución de poder; y por otro lado, el 
objetivo era lograr el control geográfico de ciertos sectores productivos. Además, demuestra que los sindicatos ortodoxos tenían espacios de acción amplios y afirma que más allá de un grupo minoritario, que buscaba tener estrategias de confrontación con el régimen, la mayor parte contribuyó a la estabilidad tanto nacional como internacional del mismo. En la tercera y última parte del artículo se detiene en una reseña de las nuevas áreas de preocupación que se vienen investigando.

El capítulo ocho se titular "Peronism in the Transition and Peronism in Transition: From the end of the Reorganization Process to the Peronist Renovation (1981-1989)”. Escrito por Joaquín Baeza Belda, aborda las transformaciones que sufrió el peronismo en el último momento de la dictadura y la transición (1981-1989).El autor logra trazar las tensiones y diferencias al interior del PJ a lo largo de todo el período, desde el momento en el cual tanto la persecución política como la falta de un liderazgo unificado generaron transformaciones en el mismo, hasta la cristalización de estas tensionesdurante la transición democrática, en los sectores renovador y ortodoxo.Lo destacable del capítulo es el recorrido que hace el autor por algunos hechos políticos en el período (la Multipartidaria Nacional, la audiencia con Viola, la Guerra de Malvinas, las leyes de amnistía, el alfonsinismo e incluso el indulto a los militares) y cómologra rescatar las distintas posturas que se presentaban al interior del peronismo. Al detenerse en la discusión por la democratización interna del partido durante la transición, el autor plantea que la conformación de las dos alas (ortodoxa y renovadora) respondía más a una lucha de poder antes que a un debate deideas, pero que dicha disputa permitió una transformación al interior del partido.

El capítulo nueve se titula "Malvinas/Falklands War: Changes in the Idea of Nation hood, the Local and National, in a Post-Dictatorship Context - Argentina 1982-2007”, y fue escrito por Federico Lorenz. Este autor ofrece una visión general sobre el periodo histórico en el quese consolidaron estos imaginarios (periodo inmediato de la postguerra) y sus legados políticos culturales y regionales. Para ello comienza planteando lo multifacético del símbolo (ya que fusiona tanto la experiencia de la guerra como la del sentimiento de usurpación) y la poca atención que le prestaron los investigadores a esta característica.

Una de las tensiones más importantes que el autor destaca sobre el contexto de la dictadura y la guerra es que esteimplicóun desafío en el culto republicano patriótico, que se instala en todo el siglo XX. Para demostrarlo el autor trae a colación diferentes casos que van desde las medidas del alfonsinismo frente al levantamiento de los carapintada, hasta las actividades relacionadas a los 25 años de la guerra de Malvinas, donde rescata nuevamente la tensión entre pensar a los soldados de Malvinas como héroes o reflexionar también acerca de la participación de muchos oficiales en la represión sistemática del régimen dictatorial.

A través de la descripción de las temáticas abordadas en los capítulos se puede dar cuenta de la renovación que ha tenido el área de los estudios acerca de la dictadura argentina en los primeros decenios del siglo XXI y cómo, a través de la desclasificación de documentos, las modificaciones en la escala, en los objetos de estudios y en las preguntas realizadas, se puede avanzar en una mayor comprensión del periodo estudiado. Esto es importante, en tanto que, si bien la dictadura como forma institucional finalizó en 1983, sus innumerables efectos resonantes en el presente no lo hicieron, sino que se inscriben dentro de este ya mencionado "pasado que no pasa”. La búsqueda de este libro es contribuir a entender y cerrar este legado, con el objetivo de obtener justicia.

Por último, y para cerrar, quiero destacar que el hecho de que el libro se haya editado en inglés, en una universidad del norte global, es un dato relevante pues permite traspasar las fronteras idiomáticas para situarse en la discusión internacional, invitando, como dicen los autores, a "actualizar el campo de la investigación comparativa usando el caso argentino como ayuda para repensar otras experiencias en América Latina y más allá." (p.18). 